\title{
Cardiac work-up protocol for liver transplant candidates: Experience from a single liver transplant centre
}

\author{
Carrie Ye $M D^{1,2}$, Meghana Saincher $M D^{1,2}$, Puneeta Tandon MD FRCPC ${ }^{1,2}$, Glenda Meeberg RN BSCN ${ }^{1,2}$, \\ Randy Williams MD FRCPC ${ }^{3}$, Kelly W Burak MD FRCPC ${ }^{4}$, Vincent G Bain MD FRCPC 1,2
}

\begin{abstract}
C Ye, M Saincher, P Tandon, et al. Cardiac work-up protocol for liver transplant candidates: Experience from a single liver transplant centre. Can J Gastroenterol 2012;26(11):806-810.
\end{abstract}

BACKGROUND: Ischemic cardiac events can cause significant morbidity and mortality postliver transplantation; however, no validated protocols to screen patients before transplantation exist.

OBJECTIVES: To report the introduction of a noninvasive cardiac screening protocol used at the Liver Unit, University of Calgary (Calgary, Alberta); to determine whether the protocol decreases use of coronary angiograms; and to compare cardiac outcomes using the new protocol with an appropriately matched historical control group.

METHODS: A new cardiac screening protocol was introduced into the program in 2005, which uses perfusion scintigraphy to screen highrisk cardiac patients, reserving coronary angiograms for abnormal results. Transplanted patients screened using this protocol were compared with matched historical controls. Electronic charts were reviewed for cardiac outcomes intra- and postliver transplantation.

RESULTS: A total of 396 patients were screened between April 2005 and February 2009. Eighty-two were transplanted by February 2009 and included in the study. Eighty-one patients were successfully matched according to age, sex, cardiac history and presence of diabetes. Twelve of $82(14.6 \%)$ and 11 of $81(13.6 \%)$ in the study and control groups, respectively, underwent coronary angiograms $(\mathrm{P}=0.85)$. Coronary artery disease was found in six of $12(50.0 \%)$ study patients and three of $11(27.3 \%)$ control patients who underwent coronary angiography $(\mathrm{P}=0.27)$. The mean $( \pm \mathrm{SD})$ length of the follow-up period was $1.87 \pm 0.91$ years and $4.45 \pm 1.89$ years in the study and control groups, respectively. One of 81 in the control group and zero of 82 in the study group experienced an acute coronary syndrome event postoperatively. CONCLUSIONS: Coronary events are infrequent in liver transplant recipients. The described protocol is an effective method of coronary artery disease screening before liver transplant but does not reduce the number of cardiac investigations performed.

Key Words: Acute coronary syndrome; Coronary angiogram; Coronary artery disease; Liver transplantation; Myocardial perfusion imaging

Coronary artery disease (CAD) continues to be one of the leading causes of mortality worldwide, especially in North America. Originally, it was believed that liver cirrhosis was protective against $\mathrm{CAD}$, but later evidence suggested that patients with end-stage liver disease may actually be at increased risk for CAD. The prevalence of significant CAD ( $>70 \%$ stenotic lesion on selective coronary angiography $[\mathrm{SCA}]$ ) in patients being considered for orthotopic liver transplantation ranges from $7.1 \%$ to $28 \%(1-4)$. Ischemic cardiac events have been described to be major contributors to morbidity and mortality in patients with significant CAD postliver transplantation (5) and may greatly increase overall mortality and morbidity rates, especially in the early postoperative period (6).

\section{Un protocole de bilan cardiaque chez les candidats à une transplantation hépatique : l'expérience d'un seul centre de transplantation cardiaque}

HISTORIQUE : Les cardiopathies ischémiques peuvent provoquer une importante morbidité et mortalité après une transplantation cardiaque. Cependant, il n'existe pas de protocole validé pour dépister les patients avant la transplantation.

OBJECTIFS : Rendre compte de l'adoption d'un protocole de dépistage cardiaque non effractif utilisé à l'unité hépatique de l'université de Calgary, en Alberta, déterminer si ce protocole réduit l'utilisation des coronarographies et comparer les issues cardiaques à l'aide du nouveau protocole au moyen d'un groupe témoin rétrospectif correctement apparié.

MÉTHODOLOGIE : Un nouveau protocole de dépistage cardiaque a été implanté dans le programme en 2005, lequel fait appel à la scintigraphie de perfusion pour dépister les patients cardiaques à haut risque, réservant les coronarographies aux résultats anormaux. Les patients greffés subissant un dépistage au moyen de ce protocole étaient comparés à des sujets témoins rétrospectifs. On a examiné les dossiers électroniques afin de constater les issues cardiaques pendant et après la transplantation hépatique.

RÉSULTATS : Au total, 396 patients ont subi le dépistage entre avril 2005 et février 2009. Quatre-vingt-deux avaient subi une transplantation en février 2009 et ont participé à l'étude. Quatre-vingt-un patients ont été appariés selon l'âge, le sexe, les antécédents cardiaques et la présence de diabète. Douze des 82 patients $(14,6 \%)$ du groupe à l'étude et 11 des 81 patients $(13,6 \%)$ du groupe témoin, respectivement, ont subi une coronarographie $(\mathrm{P}=0,85)$. On a relevé une cardiopathie chez six des $12(50,0 \%)$ patients à l'étude et trois des $11(27,3 \%)$ sujets témoins qui ont subi une coronarographie $(\mathrm{P}=0,27)$. Le suivi moyen $( \pm \mathrm{E} T)$ était d'une durée de $1,87 \pm 0,91$ ans et de $4,45 \pm 1,89$ ans au sein du groupe à l'étude et du groupe témoin, respectivement. Un patient sur les 81 du groupe témoin et aucun sur les 82 du groupe à l'étude ont subi un syndrome coronarien aigu après l'opération.

CONCLUSIONS : Les cardiopathies sont peu fréquentes chez les greffés hépatiques. Le protocole décrit est une méthode efficace de dépistage des coronaropathies avant une transplantation cardiaque, mais il ne réduit pas le nombre d'examens cardiaques effectués.

Although the general consensus is that all patients being considered for liver transplantation should be screened for CAD, it is not well established who should be screened beyond history, physical examination, electrocardiogram (ECG) and chest x-ray, and which investigative tools should be used. Current testing modalities include the exercise stress test, myocardial scintigraphy, dobutamine stress echocardiography and selective coronary angiography. At the Liver Unit, University of Alberta (Edmonton, Alberta), many patients with cardiac risk factors were being referred for selective coronary angiography for CAD screening, but it was unclear whether this invasive - and potentially nephrotoxic - testing modality was warranted. Thus, we introduced a structured cardiac screening protocol based on a noninvasive cardiac

${ }^{1}$ Liver Unit; ${ }^{2}$ Department of Medicine; ${ }^{3}$ Division of Cardiology, Department of Medicine, Royal Alexandra Hospital, University of Alberta, Edmonton;

${ }^{4}$ Liver Unit, Department of Medicine, University of Calgary, Calgary, Alberta

Correspondence: Dr Vincent G Bain, Liver Unit, Department of Medicine, 1-55 Zeidler Building, 130 University Campus, University of Alberta,

Edmonton, Alberta T6G 2X8. Telephone 780-492-8128, fax 780-492-8130, e-mail vince.bain@ualberta.ca

Received for publication December 30, 2011. Accepted March 10, 2012 
screening modality that would limit the use of coronary angiography to a well-defined group of high-risk patients.

\section{METHODS}

The present analysis was a retrospective study of a single liver transplant centre's cardiac screening protocol using historical matched controls. The study was submitted to the University of Alberta Ethics Board and approved before initiation (Ethics approval 6696). Starting April 2005, all patients with end-stage liver disease referred to the centre for transplantation were screened using the cardiac screening protocol (Figure 1). This involved a detailed cardiac history, including symptoms of ischemic cardiac disease, previous coronary interventions, history of noncardiac atherosclerotic disease (including transient ischemic attacks, strokes, peripheral vascular disease) and risk factors for CAD, including smoking, diabetes mellitus, family history of premature cardiovascular disease and hypertension. This information was gathered prospectively at the time of each transplant assessment and recorded on a specially designed worksheet to ensure completeness. A physical examination seeking evidence of cardiac dysfunction was performed. All patients underwent a standard 12-lead ECG, chest $\mathrm{x}$-ray and fasting lipid profile. Echocardiograms were obtained in selected patients if valvular disease or cardiomyopathy was suspected and were reviewed for findings consistent with ischemic heart disease.

As per the cardiac protocol, a stress (predominantly dipyridamole but also a small number of exercise and dobutamine) sestamibi myocardial perfusion scintigram (stress $\mathrm{MIBI}$ ) was obtained in patients who were diabetic; had demonstrated noncardiac atherosclerotic disease, including cerebrovascular accident and peripheral vascular disease; had two or more CAD risk factors including age $>50$ years, hypertension, positive family history (defined as a diagnosis of CAD in a first-degree relative before the age of 60 years), smoker (or quit $<3$ years previously) and dyslipidemia (low-density lipoprotein [LDL] $>4.1 \mathrm{mmol} / \mathrm{L}$ in patients without cholestatic liver disease); or underwent an ECG showing evidence suggestive of previous infarction ( $Q$ wave or bundle branch block).

SCA was reserved for patients who had an abnormal stress myocardial perfusion scintigram (presence of any reversible perfusion defect), experienced a previous myocardial infarction (MI) or known CAD, exhibited typical cardiac ischemia symptoms or demonstrated wall motion abnormalities on echocardiogram suggestive of ischemic cardiac disease.

Patients who had been screened by this protocol and transplanted by February 2009 were matched to historical controls transplanted from February 2002 to December 2005 and screened before the implementation of the new cardiac screening protocol. Before the implementation of this protocol, referrals to cardiologists for either opinion or SCA were based on the gestalt of the liver transplantation team as to whether the patient was at high risk of postoperative MI and not based on any guideline or algorithm.

Matching was based on age (within a difference of one year), sex, cardiac history (known CAD or history of MI) and presence of diabetes mellitus, having to meet at least the first two criteria and one or more of the last two criteria. These patients' electronic charts were reviewed for baseline characteristics, cardiac risk factors, cardiac work-up results, coronary interventions, intraoperative cardiac events and postoperative acute coronary syndrome events.

\section{Statistical analysis}

Continuous variable data were reported as mean \pm SD and were compared using the $t$ test for independent samples. Categorical data were reported as number of subjects (percentages) and compared using the Pearson two-sided $\chi^{2}$ test. Kaplan-Meier methodology was used to assess differences in survival between study and matched control patients. Survival curves were compared using the log-rank test. Statistical significance was established at $\mathrm{P}<0.05$ and all reported $\mathrm{P}$ values were two tailed. All statistical analyses were performed using SPSS version 18.0 (IBM Coproration, USA).

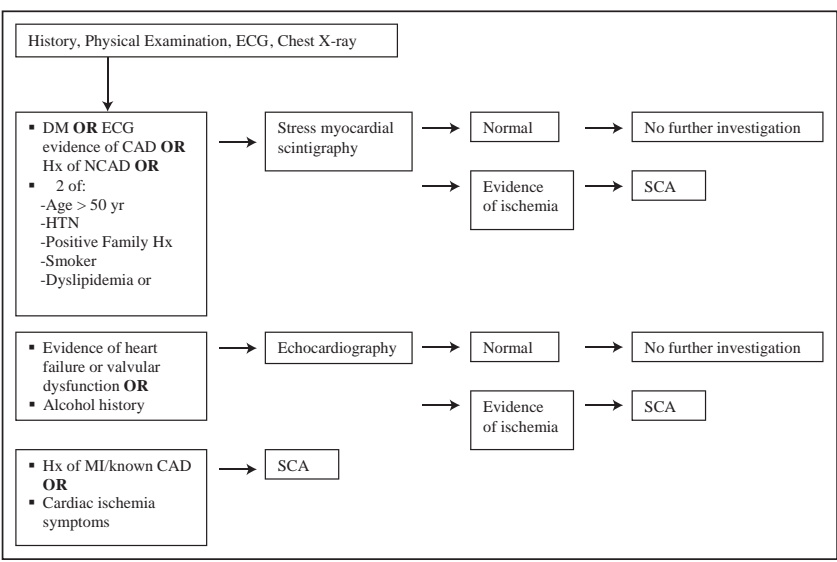

Figure 1) Cardiac workup protocol for liver transplant candidates. The flow sheet summarizes the coronary artery disease screening protocol that all study patients underwent before liver transplantation. CAD Coronary artery disease; DM Diabetes mellitus; ECG Electrocardiogram; HTN Hypertension; Hx History; MI Myocardial infarction; NCAD Noncardiac atherosclerotic disease; SCA Selective coronary angiography

\section{RESULTS}

Of the 396 patients who were evaluated with this cardiac screening protocol from April 2005 to February 2009, 82 patients received a liver transplant by February 2009. Of the remaining 314 patients, 101 were found to be unsuitable for transplant, three of which were principally due to CAD; 25 on the wait list died; 15 were delisted for deterioration; 43 were delisted for improvement or developing a new contraindication for transplant (such as noncompliance, substance abuse, extrahepatic malignancy) and 130 were still awaiting transplant. Matching to historical controls based on age, sex, cardiac history and presence of diabetes mellitus was successful in 81 of the 82 patients. Baseline characteristics of both groups are summarized in Table 1 . There were no significant differences (ie, $\mathrm{P}<0.05$ ) between the control group compared with the study group aside from mean high-density lipoprotein (HDL) levels, which were significantly lower in the study group $(0.93 \mathrm{mmol} / \mathrm{L}$ versus $1.34 \mathrm{mmol} / \mathrm{L} ; \mathrm{P}=0.03)$.

Of the three patients who were excluded from transplant due principally to CAD in the protocol group, one patient had an abnormal stress myocardial perfusion scan and CAD on angiography, which, along with left ventricular dysfunction, excluded the patient from transplant. The second patient exhibited severe triple vessel disease on coronary angiogram and underwent surgical revascularization, with subsequent postoperative complications. The third patient experienced a recent MI, and SCA showed severe left main coronary artery disease. He was scheduled for coronary artery bypass graft (CABG), surgery but was clinically unstable, in heart failure and required inotropic support. This patient later died in the coronary care unit.

Of the 396 patients who were evaluated before April 2005, three patients were excluded principally due to CAD. The first patient had a history of MI, with ongoing typical anginal chest pain and poor compliance to investigations and therapy. The second patient had a stress myocardial perfusion scan that was negative for ischemic changes, but still went on to angiography, which showed moderate diffuse CAD, which, along with morbid obesity, diabetes, hypertension and older age, excluded the patient from transplant. The third patient had a history of MI, typical anginal chest pain and SCA showing severe triple vessel disease requiring CABG surgery. However, the patient was noncompliant with tests and never received a CABG surgery, thus preventing the patient from being listed for transplantation.

Of the 82 transplanted patients in the new protocol study group, three had a history of MI and underwent SCA. One patient did not meet the criteria for SCA but had it performed in breach of protocol. Of the four patients who went directly for SCA, three patients had no evidence of CAD and one patient had mild to moderate CAD that did not require percutaneous coronary angioplasty (PCA). 
TABLE 1

Baseline characteristics

\begin{tabular}{|c|c|c|c|}
\hline \multirow[b]{2}{*}{ Characteristic } & \multicolumn{2}{|c|}{ Group } & \multirow[b]{2}{*}{$\mathbf{P}$} \\
\hline & Control $(n=81)$ & Study $(n=82)$ & \\
\hline \multicolumn{4}{|l|}{ Demographic } \\
\hline Age, years, mean \pm SD & $52.0 \pm 10.6$ & $52.3 \pm 10.3$ & 0.83 \\
\hline Age >50 years, $\mathrm{n}(\%)$ & 58 (71.6) & $59(72.0)$ & 1.00 \\
\hline Male sex, n (\%) & $58(71.6)$ & $58(73.2)$ & 0.82 \\
\hline $\mathrm{BMI}, \mathrm{kg} / \mathrm{m}^{2}$, mean $\pm \mathrm{SD}$ & $26.4 \pm 5.1$ & $26.3 \pm 4.2$ & 0.94 \\
\hline \multicolumn{4}{|l|}{ ESLD etiology*, n (\%) } \\
\hline Hepatitis C virus & $29(35.8)$ & $35(42.7)$ & 0.37 \\
\hline Hepatitis B virus & $5(6.2)$ & $3(3.7)$ & 0.46 \\
\hline Alcohol & 35 (43.2) & $29(35.4)$ & 0.31 \\
\hline Cryptogenic & $9(11.1)$ & $4(4.9)$ & 0.14 \\
\hline PSC & $5(6.2)$ & $9(11.0)$ & 0.27 \\
\hline PBC & $8(9.9)$ & $5(6.1)$ & 0.37 \\
\hline Autoimmune & $2(2.5)$ & $5(6.1)$ & 0.25 \\
\hline Alpha-1-AT deficiency & $2(2.5)$ & $3(3.7)$ & 0.66 \\
\hline Hepatocellular carcinoma & $17(21.0)$ & $21(25.6)$ & 0.49 \\
\hline $\mathrm{NASH}$ & $1(1.2)$ & $2(2.4)$ & 1.00 \\
\hline Other & $11(13.6)$ & $8(9.8)$ & 0.47 \\
\hline MELD score, mean \pm SD & $18 \pm 9$ & $18 \pm 9$ & 0.87 \\
\hline \multicolumn{4}{|l|}{ Cardiac profile, n (\%) } \\
\hline History of MI & $4(4.9)$ & $3(3.7)$ & 0.72 \\
\hline Diabetes & $15(18.5)$ & $17(20.7)$ & 0.72 \\
\hline Smoker & $40(49.4)$ & $39(47.6)$ & 0.82 \\
\hline Hypertension & $20(24.7)$ & $18(22.0)$ & 0.68 \\
\hline Family history & $19(23.5)$ & $15(18.5)$ & 0.44 \\
\hline \multicolumn{4}{|c|}{ Lipid profile, mmol/L, mean \pm SD } \\
\hline LDL & $2.44 \pm 2.11$ & $2.05 \pm 1.03$ & 0.15 \\
\hline HDL & $1.34 \pm 1.59$ & $0.93 \pm 0.43$ & 0.03 \\
\hline Triglycerides & $1.12 \pm 0.71$ & $1.03 \pm 0.67$ & 0.44 \\
\hline
\end{tabular}

*Total number of end-stage liver disease (ESLD) etiologies is more than the total number of patients in both groups because some patients had more than one diagnosis. AT Antitrypsin; BMI Body mass index; HDL High-density lipoprotein; LDL Low-density lipoprotein; MELD Model for End-stage Liver Disease; MI Myocardial infarction; NASH Nonalcoholic steatohepatitis; PBC Primary biliary cholangitis; PSC Primary sclerosing cholangitis

As summarized in Table 2, seven patients in the study group had ECG findings consistent with ischemia or old MI. In total, 54 of the 82 patients in the study group met criteria for stress myocardial scintigraphy. Of these 54 patients, eight had abnormal myocardial scans and proceeded to undergo SCA. Of these eight SCAs, five showed evidence of CAD, but none were sufficiently severe to warrant PCA. In total, 12 angiograms were performed in the 82 patients in the study group, with six revealing $\mathrm{CAD}$ and none revealing severe $\mathrm{CAD}$ requiring $\mathrm{PCA}$ or CABG. There was no significant difference between the two groups in the number of SCAs performed (11 [13.6\%] versus 12 [14.6\%] respectively; $\mathrm{P}=0.85)$, but there was a significant increase in the number of stress myocardial perfusion scans performed in the study group (54 [65.9\%] versus 39 [48.1\%]; $\mathrm{P}=0.03$ ). The proportion of positive stress myocardial perfusion scans was not significantly different between the two groups $(\mathrm{P}=0.52)$.

The proportion of SCAs showing at least mild CAD was higher in the study group compared with the control group, but did not reach statistical significance (six of 12 [50.0\%] versus three of 11 [27.3\%], respectively; $\mathrm{P}=0.27$ ). The number of critical lesions ( $>70 \%$ stenosis) requiring $\mathrm{PCA}$ was higher in the control group, with two patients receiving intracoronary stents compared with none in the study group. No patients in the study had CAD sufficient to warrant a CABG.

Post-transplant follow-up for the study group ranged from 0.36 to 3.66 years, with an average of 1.87 years, compared with 3.41 to 7.11 years, with an average of 4.45 years for the control group. No patients in the study group experienced a peri- or postoperative event related to CAD compared with one patient in the control group. This patient
TABLE 2

Summary of cardiac investigations performed and results in both the control and study groups

\begin{tabular}{lccc}
\hline & \multicolumn{2}{c}{ Group } & \\
\cline { 2 - 3 } Test & \multicolumn{1}{c}{ Control } & Study & P \\
\hline ECG evidence of CAD & $5 / 81(6.2)$ & $7 / 82(8.5)$ & 0.77 \\
Stress MIBI performed & $39 / 81(48.1)$ & $54 / 82(65.9)$ & 0.03 \\
Proportion of MIBI that were positive* & $4 / 39(10.3)$ & $8 / 54(14.8)$ & 0.52 \\
Selective coronary angiography & $11 / 81(13.6)$ & $12 / 82(14.6)$ & 0.85 \\
Proportion of SCA with CAD & $3 / 11(27.3)$ & $6 / 12(50.0)$ & 0.27 \\
Proportion of SCA with $>70 \%$ stenosis & $2 / 11(18.2)$ & $0 / 12(0.0)$ & 0.15 \\
$\quad$ & & &
\end{tabular}

Data presented as $n / n$ (\%) unless otherwise indicated. *A positive stress sestamibi myocardial perfusion scintigram (MIBI) was defined as one or more areas of reversible defect. CAD Coronary artery disease; ECG Electrocardiogram; PCA Percutaneous coronary angioplasty; SCA Selective coronary angiography

TABLE 3

Postoperative outcomes

\begin{tabular}{|c|c|c|c|}
\hline \multirow[b]{2}{*}{ Outcome } & \multicolumn{2}{|c|}{ Group } & \multirow[b]{2}{*}{$\mathbf{P}$} \\
\hline & Control $(n=81)$ & Study $(n=82)$ & \\
\hline Follow-up, years, mean \pm SD & $4.45 \pm 1.89$ & $1.87 \pm 0.91$ & $<0.0001$ \\
\hline Peri- and postoperative ACS, n (\%) & $1(1.2)$ & $0(0)$ & 0.50 \\
\hline $\begin{array}{l}\text { Peri- and postoperative mortality } \\
\text { related to CAD, } \mathrm{n}(\%)\end{array}$ & $0(0)$ & $0(0)$ & 1.00 \\
\hline Survival, $\% \pm \mathrm{SE}$ & & & $0.22^{\star}$ \\
\hline Three-month & $98.8 \pm 1.2$ & $96.3 \pm 2.1$ & \\
\hline Six-month & $93.8 \pm 2.7$ & $90.2 \pm 3.3$ & \\
\hline 12-month & $92.6 \pm 2.9$ & $89.0 \pm 3.5$ & \\
\hline 24-month & $82.7 \pm 4.2$ & $89.0 \pm 3.5$ & \\
\hline 60-month & $65.9 \pm 5.7$ & - & \\
\hline
\end{tabular}

* Log-rank test. Summary of postoperative outcomes, including ischemic cardiac disease associated morbidity and mortality, and survival data for both the control and study groups. ACS Acute coronary syndrome; CAD Coronary artery disease

did not have a cardiac history or cardiac risk factors other than age, but underwent a pretransplant ECG showing left anterior hemifascicular block. Echocardiogram was normal, but a stress myocardial perfusion scan or SCA were not performed. One day post-transplantation, this patient developed pulmonary edema, a new pansystolic murmur lasting approximately $30 \mathrm{~min}$, associated with a slight troponin rise $(0.18 \mathrm{ng} / \mathrm{mL})$, but no ECG changes. Cardiology was consulted and this episode was believed to be ischemic mitral regurgitation.

Overall, survival for these patients in both groups is summarized in Table 3. There was no significant difference in survival at three, six, 12 and 24 months post-transplant. The Kaplan-Meier survival curve is shown in Figure 2.

\section{DISCUSSION}

Morbidity and mortality related to CAD in liver transplant candidates have been believed to be a significant concern. In a study involving 32 patients undergoing liver transplantation with known severe CAD (stenosis $>70 \%$ ), the overall mortality rate was $50 \%$ with one-half of the deaths occurring within the first 35 days postliver transplantation (6). This, combined with a study showing a $27 \%$ incidence of moderate to severe CAD in liver transplant candidates (1), makes screening for CAD a routine part of the work-up in most liver transplantation programs.

There is no consensus on the best approach to screening for CAD in this population. The American Heart Association has published guidelines on CAD screening before noncardiac surgery based on poor exercise tolerance (7); however, its relevance for liver transplantation is unclear because liver failure patients have many reasons aside from poor cardiac function to have poor exercise tolerance. The important questions are which patients should be screened and how should they be screened. 
We chose to screen asymptomatic high-risk patients, as defined by the presence of the known CAD risk factors, found in the current Canadian Cardiovascular Society guidelines (8). Although we are confident that these risk factors account for the majority of CAD cases, our study would suggest that given the very small number of postoperative MIs, these risk factors do not necessarily translate to postoperative cardiac morbidity and mortality and, thus, may not warrant pretransplant screening. A study by Fili et al (9), using a risk factorbased protocol in an Italian cohort also found no cases of critical CAD defined as stenosis $\geq 70 \%$. They concluded that symptom history was the most important aspect of CAD workup and no longer screen using other noninvasive methods based on risk factors alone.

Even if we were able to establish the population that needs further investigation, the optimal noninvasive test in this patient population remains unclear. Donovan et al (10) found that dobutamine stress echocardiogram (DSE) was $75 \%$ sensitive and $57 \%$ specific for identifying CAD when using coronary angiography as the gold standard. However, there appears to be no difference in intraoperative myocardial injury or global left ventricular dysfunction between patients with positive DSE and negative DSE, with one study showing a sensitivity and specificity of $20 \%$ and $90 \%$, respectively, for predicting intraoperative myocardial injury based on elevations of troponin levels $(10,11)$. In comparison, stress myocardial perfusion imaging (MPI), was shown to have a sensitivity of $37 \%$ and a specificity of $63 \%$ in a study of 83 liver transplant candidates without a previous history of CAD, using coronary angiogram as the gold standard (12). However, a normal stress myocardial perfusion scan has been shown to identify patients at very low risk for early and late cardiac events, with a negative predictive value of $99 \%$ (13). There are no head-to-head trials comparing DSE and stress MPI for predicting CAD, or intraoperative and postoperative prognosis. We chose stress MPI in our protocol based on greater accessibility at our centre.

In our study using stress MPI as our noninvasive screening tool, the majority of positive tests for CAD were confirmed on SCA, but none of the SCAs showed sufficiently severe disease to require PCA, suggesting that an extensive and expensive workup is unnecessary in asymptomatic patients. However, it can be argued that because the diagnosis of mild to moderate CAD resulted in medical therapy, this result could have potentially reduced the number of postoperative cardiac events.

In total, 12 angiograms were performed in the study group, one in breach of protocol, which was negative for CAD. Six of the 11 patients selected to undergo SCA based on the protocol had CAD compared with three of 11 in the control group. Although we did not realize a reduction in the number of SCAs performed, our new protocol for selecting high-risk patients who need stress MPI and SCA appears to perform better than our previous nonalgorithmic use of SCA.

There were no ischemic cardiac events in the study group and the one patient in the control group who experienced a postoperative cardiac event would have received further cardiac workup based on the screening ECG, which may have resulted in interventions that may have prevented this event. Based on the absence of postoperative ischemic cardiac morbidity and mortality compared with predominantly older literature, which reports postoperative ischemic cardiac events to be $5 \%$ to $13 \%(14-16)$, we were surprised to find the lack of coronary events in both the study by Fili et al (9) and our own. There are three possible explanations that are not mutually exclusive. Our screening resulted in medical therapy, such as starting and continuing acetylsalicylic acid in the postoperative period, which may have decreased the number of coronary events. Second, patients with significant cardiac disease may have been screened and excluded from referral for transplant assessment by their hepatologists or internists and, thus, our study underestimates the incidence of CAD in this population. Finally, the literature may reflect differences in definition of postoperative MI. In the past 10 years, the understanding of the different types of MIs has increased and, in 2007, Thygesen et al (17) published a new classification system for acute MI. Whereas we only included type $1 \mathrm{MIs}$, or MIs in the setting of true plaque rupture, older studies defined any rise in

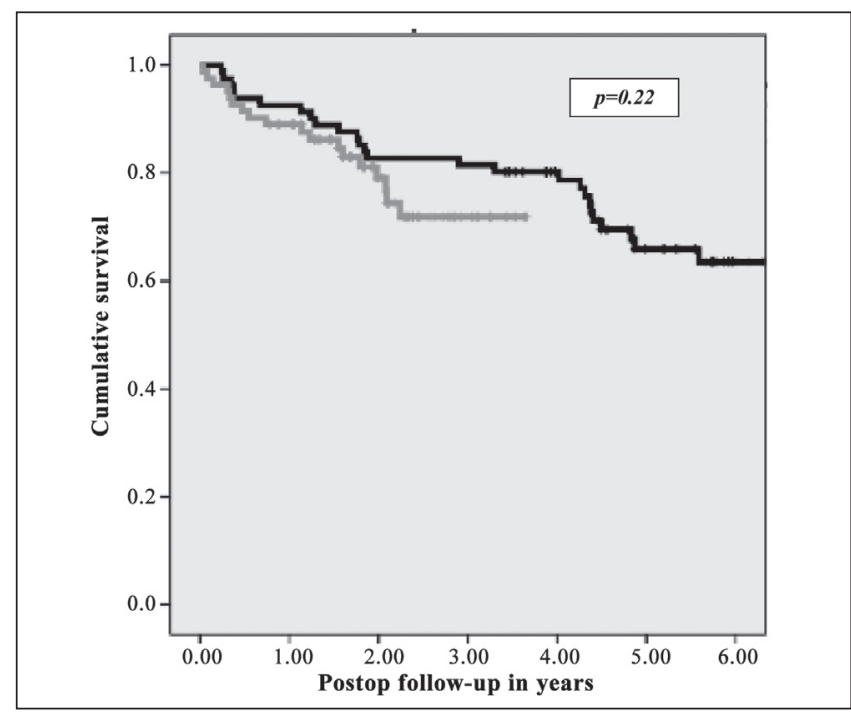

Figure 2) Kaplan-Meier curve illustrating survival postliver transplantation in both the study patients (grey) and the control patients (black). The difference in survival was not statistically significant $(P=0.22)$. Postop Postoperative

troponin level to be an acute coronary event, including type 2 MIs. Type 2 MIs occur in the setting of increased oxygen demand, which is quite common with major volume changes postliver transplantation, but does not represent an acute blockage of the coronary arteries.

It is unclear whether noninvasive cardiac screening is useful in excluding patients from liver transplantation. One study retrospectively investigated the results of screening stress MPI and their relationship with liver transplantation eligibility and found that the OR of being denied transplantation were the same for candidates with lowrisk, intermediate-risk and high-risk stress MPI results (18). However, as pointed out by the authors, a decisive effect of MPI for patient exclusion may have been diluted by the presence of other factors that also excluded the patient from liver transplant candidacy.

We realize the limitations of a historical matched control group, including changing patient population, evolving criteria for transplantation, evolving surgical techniques and confounding variables for which we have not matched. Furthermore, given the limited pool of patients from which we could extract controls, we were not able to match all of our patients for all four selected criteria. Despite these limitations, the historical group allowed us to show that initiating a protocol not only did not reduce the number of SCAs performed, but increased the number of noninvasive procedures performed. Despite the increase in investigations, the rarity of postoperative MIs made it very difficult to show a decrease using our protocol.

\section{CONCLUSION}

Our centre's experience with this protocol did not achieve its goal of decreasing the number of SCAs, but instead, we found that severe $\mathrm{CAD}$ appears to be less of a problem in this patient population than expected, and that postoperative morbidity and mortality attributed to $\mathrm{CAD}$ is uncommon. This raises the radical question: is CAD screening even necessary in asymptomatic patients? Our results, along with those of Fili et al (9), may be the beginning of a changing dialogue with regard to the importance or, rather, the unimportance of CAD screening in the liver transplant population. Given the significant resources spent on cardiac workup, it behooves liver transplant programs to justify this cost. Additional studies with larger patient populations are needed to examine the cost effectiveness of cardiac screening, comparisons of current screening tools to predict both $\mathrm{CAD}$ and intra- and postoperative outcomes, and the role of cardiac screening in the evolving selection criteria for liver transplantation. 


\section{REFERENCES}

1. Carey WD, Dumot JA, Pimentel RR, et al. The prevalence of coronary artery disease in liver transplant candidates over age 50 . Transplantation 1995;59:859-64.

2. Plotkin JS, Benitez RM, Kuo PC, et al. Dobutamine stress echocardiography for preoperative cardiac risk stratification in patients undergoing orthotopic liver transplantation. Liver Transpl Surg 1998;4:253-7.

3. Blei AT, Mazhar S, Davidson CJ, Flamm SL, Abecassis M, Gheorghiade M. Hemodynamic evaluation before liver transplantation: Insights into the portal hypertensive syndrome. J Clin Gastroenterol 2007;41(Suppl 3):S323-9.

4. Tiukinhoy-Laing SD, Rossi JS, Bayram M, et al. Cardiac hemodynamic and coronary angiographic characteristics of patients being evaluated for liver transplantation. Am J Cardiol 2006;98:178-81.

5. Therapondos G, Flapan AD, Plevris JN, Hayes PC. Cardiac morbidity and mortality related to orthotopic liver transplantation. Liver Transpl 2004;10:1441-53.

6. Plotkin JS, Scott VL, Pinna A, Dobsch BP, De Wolf AM, Kang Y. Morbidity and mortality in patients with coronary artery disease undergoing orthotopic liver transplantation. Liver Transpl 1996;2:426-30.

7. Fleisher LA, Beckman JA, Brown KA, et al. ACC/AHA 2007 guidelines on perioperative cardiovascular evaluation and care for noncardiac surgery: Executive summary: A report of the American College of Cardiology/American Heart Association Task Force on Practice Guidelines (Writing Committee to Revise the 2002 Guidelines on Perioperative Cardiovascular Evaluation for Noncardiac Surgery). J Am Coll Cardiol 2007;50:1707-32.

8. Genest J, McPherson R, Frohlich J, et al. 2009 Canadian Cardiovascular Society/Canadian guidelines for the diagnosis and treatment of dyslipidemia and prevention of cardiovascular disease in the adult-2009 recommendations. Can J Cardiol 2009;25:567-79.
9. Fili D, Vizzini G, Biondo D, et al. Clinical burden of screening asymptomatic patients for coronary artery disease prior to liver transplantation. Am J Transpl 2009;9:1151-7.

10. Donovan CL, Marcovitz PA, Punch JD, et al. Two-dimensional and dobutamine stress echocardiography in the preoperative assessment of patients with end-stage liver disease prior to orthotopic liver transplantation. Transplantation 1996;61:1180-8.

11. Findlay JY, Keegan MT, Pellikka PP, Rosen CB, Plevak DJ. Preoperative dobutamine stress echocardiography, intraoperative events, and intraoperative myocardial injury in liver transplantation. Transplant Proc 2005;37:2209-13.

12. Davidson CJ, Gheorghiade M, Flaherty JD, et al. Predictive value of stress myocardial perfusion imaging in liver transplant candidates. Am J Cardiol 2002;89:359-60.

13. Zoghi GJ, Patel AD, Ershadi RE, Heo J, Bynon JS, Iskandrian AE. Usefulness of preoperative stress perfusion imaging in predicting prognosis after liver transplantation. Am J Cardiol 2003;92:1066-71.

14. Borg MA, van der Wouden EJ, Sluiter WJ, Sloof MJ, Haagsma EB, van den Berg AP. Vascular events after liver transplantation: A long term follow-up study. Transpl Int 2008;21:74-80.

15. Dec GW, Kondo N, Farrell ML, Dienstag J, Cosimi AB, Semigran MJ. Cardiovascular complications following liver transplantation. Clin Transplant 1995;9:463-71.

16. Rubin DA, Schulman DS, Edwards TD, Starzl TE, Curtiss EI. Myocardial ischemia after orthotopic liver transplantation. Am J Cardiol 1994;74:53-56.

17. Thygesen K, Alpert JS, White HD. Universal definition of myocardial infarction. J Am Coll Cardiol 2007;50:2173-95.

18. Bradley SM, Soine LA, Caldwell JH, Goldberg SL. Screening stress myocardial perfusion imaging and eligibility for liver transplantation. Am J Cardiol 2010;105:1010-3. 


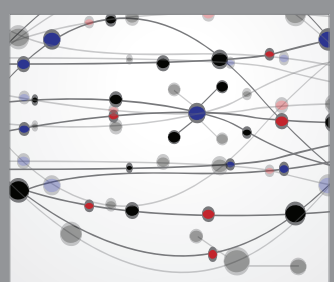

The Scientific World Journal
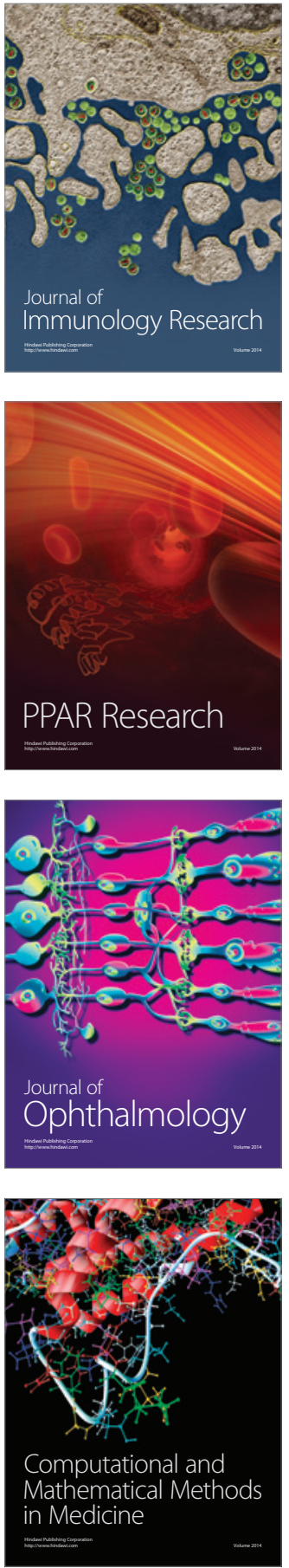

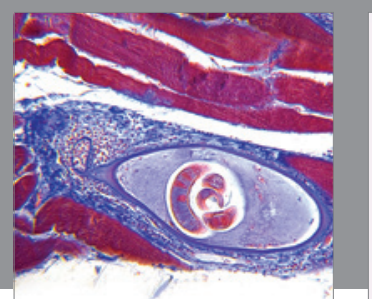

Gastroenterology Research and Practice

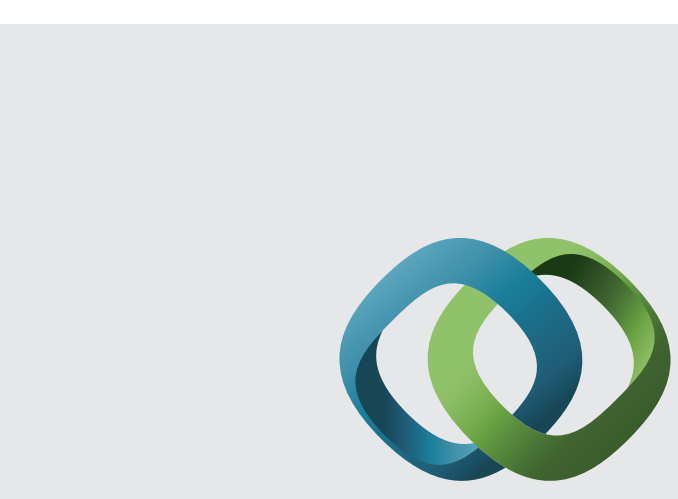

\section{Hindawi}

Submit your manuscripts at

http://www.hindawi.com
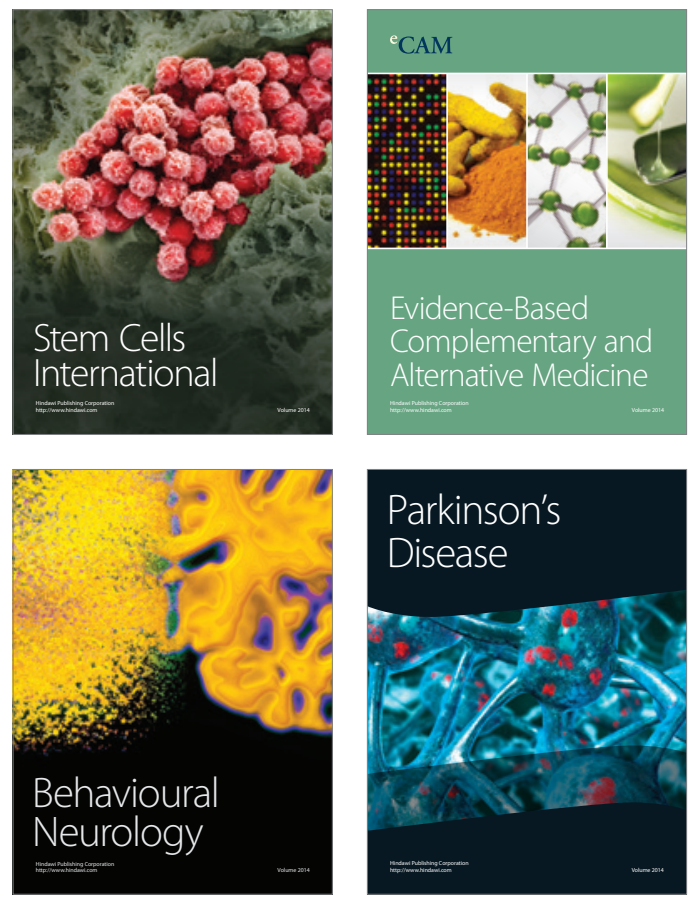
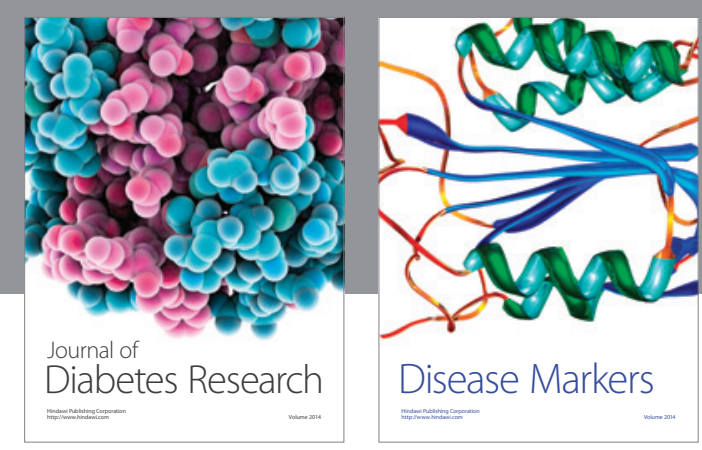

Disease Markers
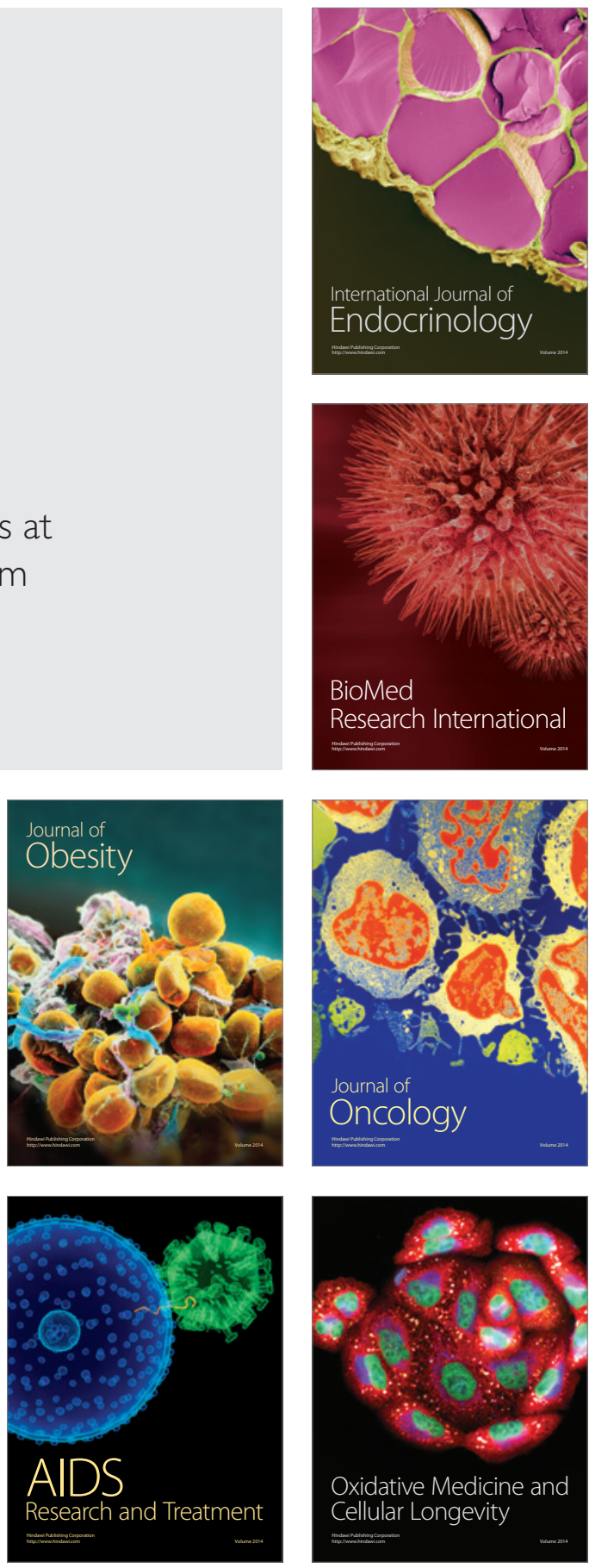